\title{
Study of Stroke in Young Adults in Vindhya Region
}

\author{
Praveen Kumar Baghel ${ }^{1}$, Keshav Singh ${ }^{2}$, Chandra Shekar Gupta ${ }^{3}$ \\ ${ }^{1}$ Department of Medicine, S.S. Medical College, Rewa, Madhya Pradesh, India. ${ }^{2}$ Department of Medicine, S.S. Medical \\ College, Rewa, Madhya Pradesh, India. ${ }^{3}$ Department of Medicine, S.S. Medical College, Rewa, Madhya Pradesh, India.
}

\section{ABSTRACT}

\section{BACKGROUND}

Stroke is the most common life threatening or disabling neurological condition in older population. Although it is not infrequent in young adults, stroke in young adults poses a major socioeconomic health problem especially in developing countries. Increased incidence of stroke in young adult is due to rise in the prevalence of diabetes mellitus, hypertension, and hypercholesterolemia. Obesity has been recognised as a risk factor in high income countries. In addition smoking, tobacco chewing and alcohol abuse are frequent in young people and have tended to increase over time. Emergent vascular risk factors may also have contributed, in part, to the increase in ischemic stroke.

\section{METHODS}

This is an observational study conducted in the Department of Medicine, Sanjay Gandhi Memorial Hospital, associated with Shyam Shah Medical College, Rewa, in the Vindhya region between April 2018 and June 2019.

\section{RESULTS}

Out of 100 patients, $73 \%$ patients presented with ischemic stroke, 58\% were males and most common clinical presentation was hemiparesis (83\%). Associated addictions were smoking, tobacco chewing and alcohol, among which smoking was statistically significant.

\section{CONCLUSIONS}

Stroke in young adults can lead to huge socioeconomic burden on society. In our study we found smoking to be a significant risk factor. So, by countering these addictions at various levels of prevention, we can decrease the incidence of stroke in young adults.

\section{KEY WORDS}

Stroke, Smoking, Young Adults
Corresponding Author:

Dr. Keshav Singh,

Associate Professor,

Department of Medicine,

S.S. Medical College,

Rewa-486001,

Madhya Pradesh, India.

E-mail: keshavsingh19@yahoo.com

DOI: $10.14260 /$ jemds/2020/213

Financial or Other Competing Interests: None.

How to Cite This Article:

Baghel PK, Singh K, Gupta CS. Study of stroke in young adults in Vindhya region. J. Evolution Med. Dent. Sci. 2020;9(12):991994, DOI: $10.14260 / \mathrm{jemds} / 2020 / 213$

Submission 01-01-2020,

Peer Review 02-03-2020,

Acceptance 09-03-2020,

Published 23-03-2020.






\section{BACKGROUND}

A stroke or cerebrovascular accident, is defined as an abrupt onset of a neurologic deficit that is attributable to a focal vascular cause lasting 24 hours or longer. ${ }^{1}$ Stroke is the most common life threatening or disabling neurological condition in older population. Although it is not infrequent in young adults. Stroke in young adults pose a major socioeconomic health problem especially in developing countries. ${ }^{2}$ It has an important contribution towards morbidity, disability and mortality in both developed as well as developing countries. Stroke is the third most common cause of mortality ${ }^{3}$ and the fourth leading cause of disease burden in the world. 4

Increase in incidence of stroke in young adults is due to rise in the prevalence of Diabetes mellitus, Hypertension, hypercholesterolemia, and obesity has been observed as common risk factor in high income countries. In addition addictions like smoking, tobacco chewing and alcohol abuse are frequent in young people and have tended to increase over time. Emergent vascular risk factors may also have contributed, in part, to the increase in ischemic stroke. Other contributing factors, such as life style modification and habits attributed to the evolution of the society, may also play a role in the rising stroke incidence in young adults and need to be explored further. Despite comprehensive evaluations, the cause of ischemic stroke remains undetermined in approximately one third of young patients called cryptogenic stroke. Further studies are required to better characterize these patients so as to identify specific features and the underlying pathophysiology of these undetermined stroke. ${ }^{5}$

The most common symptom of a stroke is sudden weakness or numbness of the face, arm, or leg, most often on one side of the body, Other symptoms include confusion, difficulty speaking or understanding speech, difficulty seeing with one or both eyes, difficulty walking, dizziness, and loss of balance or coordination, severe headache with no known cause; fainting or unconsciousness. ${ }^{2}$ Early identification of risk factors and implication of preventive measures can help in bringing down the occurrence of stroke and reduce the financial and emotional burden in the family. A dedicated evaluation for identifying the cause is needed to treat and prevent further recurrences.

We wanted to study the clinico-demographic profile of stroke in young patients with special emphasis on addictions.

\section{METHODS}

This is an observational study conducted in the Department of Medicine, Sanjay Gandhi Memorial Hospital, associated with Shyam Shah Medical College, Rewa, in the Vindhya region between April 2018 to June 2019 (15 months) with sample size was 100 cases. The study was conducted for duration of 15 months on the patients with focal/generalized neurological deficit who reported in our institution and fulfilled the inclusion criteria. We took thorough history about the personal, family details and addiction history from the participants which included the type and duration of addiction. After the process of history taking, we did clinical examination, ordered some baseline investigation like $\mathrm{CBC}$, LFT, RFT and special investigations like CT/MRI scans.
Patient's porforma was maintained which included all demographic particulars. The study was approved by Ethical Committee and informed consent was obtained. Stroke cases proven by CT scan/ MRI Brain in the age group of 18-45 years were included in the study. Patients with traumatic brain injury were excluded from the study.

\section{Statistical Methods}

Chi square test and Fisher Exact test had been used to find the significant association of risk factors with stroke. A p value $<0.05$ was considered significant.

\section{RESULTS}

\begin{tabular}{|c|c|c|c|}
\hline \multicolumn{2}{|c|}{ Type of Stroke } & Number of Patients $(n=100)$ & $\%$ \\
\hline \multicolumn{2}{|c|}{ Ischemic stroke } & 73 & 73.0 \\
\hline \multicolumn{2}{|c|}{ Haemorrhagic stroke } & 27 & 27.0 \\
\hline \multicolumn{4}{|c|}{ Table 1. Type of Stroke $(n=100)$} \\
\hline $\begin{array}{l}\text { Age in } \\
\text { Years }\end{array}$ & $\begin{array}{l}\text { Male } \\
\text { No.\% }\end{array}$ & $\begin{array}{c}\text { Female } \\
\text { No.\% }\end{array}$ & $\begin{array}{l}\text { Total } \\
\text { No. } \%\end{array}$ \\
\hline $18-25$ & 1220.69 & 1638.09 & 2828.0 \\
\hline $26-35$ & 1831.03 & 1228.57 & 3030.0 \\
\hline $36-45$ & 2848.28 & 1433.34 & 4242.0 \\
\hline Total & 58100.0 & 42100.0 & 100100.0 \\
\hline Mean \pm SD & $34.34 \pm 7.562$ & $32.55 \pm 8.986$ & $33.59 \pm 8.195$ \\
\hline \multicolumn{4}{|c|}{ Table 2a. Demographic Distribution } \\
\hline
\end{tabular}

\begin{tabular}{|ccc|}
\hline Habitat Area & Number of Patients & $\%$ \\
Rural & 56 & 56.0 \\
Urban & 44 & 44.0 \\
Total & $\mathbf{1 0 0}$ & $\mathbf{1 0 0 . 0}$ \\
\hline \multicolumn{3}{|c|}{ Table 2b. Demographic Distribution } \\
\hline
\end{tabular}

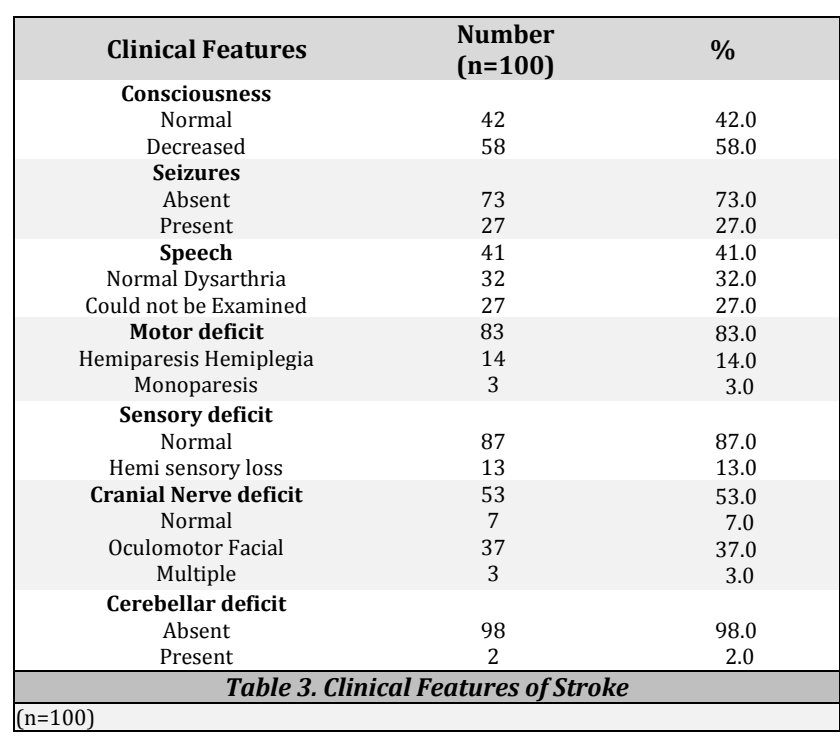

\begin{tabular}{|c|c|c|c|}
\hline \multirow[b]{2}{*}{ Risk Factors } & \multicolumn{2}{|c|}{ Type of Stroke } & \multirow[b]{2}{*}{$\mathbf{p}$} \\
\hline & $\begin{array}{l}\text { Ischemic Stroke } \\
\qquad(n=73)\end{array}$ & $\begin{array}{l}\text { Haemorrhagic Stroke } \\
\qquad(n=39)\end{array}$ & \\
\hline \multicolumn{4}{|l|}{ Smoking } \\
\hline Absent & $44(60.3 \%)$ & $23(85.2 \%)$ & 0.02 \\
\hline Present & $29(39.7 \%)$ & $4(14.8 \%)$ & \\
\hline \multicolumn{4}{|l|}{ Tobacco chewing } \\
\hline Absent & $48(65.8 \%)$ & $22(81.5 \%)$ & 0.14 \\
\hline Present & $25(34.2 \%)$ & $5(18.5 \%)$ & \\
\hline \multicolumn{4}{|l|}{ Alcohol } \\
\hline Absent & $51(69.9 \%)$ & $17(63.0 \%)$ & 0.62 \\
\hline Present & $22(30.1 \%)$ & $10(37.0 \%)$ & \\
\hline \multicolumn{4}{|c|}{ Table 4. Correlation of Various Addictions with Type of Stroke } \\
\hline
\end{tabular}

A total of 100 consecutive patients diagnosed with stroke satisfying inclusion and exclusion criteria were selected for the study. In this study $73 \%$ of all stroke cases were ischemic 
stroke patients where as $27 \%$ of them had hemorrhagic stroke. Sex ratio in our study was 1.3:1 (male: female). The Mean age \pm SD of the study group was $33.59 \pm 8.195$ years and that of male and female patients was $34.34 \pm 7.562$ years and $32.55 \pm 8.986$ years respectively. The majority of the strokes occurred between the ages of 36-45 years at $42 \%$ and $48.28 \%$ of male were also in the same age group, whereas in females it was in the ages between 18-25 years at 38.09\%. The incidence of stroke was slightly higher in the rural population $(56 \%)$ as compared to urban population (44\%). $58 \%$ of the study patients presented with decrease level of consciousness, $27 \%$ patients presented with seizures, $32 \%$ of patients had speech abnormalities. Motor deficit was seen in all the patients, hemiparesis seen in $83 \%$ patients, hemiplegia seen in $14 \%$ patients and monoparesis seen in $3 \%$ patients. Hemisensory loss was seen in $13 \%$ of the study group. The most common cranial nerve affected was the facial nerve in $37 \%$ and $7 \%$ of the patients had the occulomotor nerve affected and $3 \%$ of the study group had other cranial nerve palsies. Only $2 \%$ of the patients had cerebellar deficit. $33 \%$ of all the patients were smokers. Among the ischemic and the hemorrhagic stroke $39.7 \%$ and $14.8 \%$ were smoker respectively, this was significant ( $p$ value $=0.02$ ). $30 \%$ of the patients were tobacco chewers. Among the ischemic and the hemorrhagic stroke patients $34.2 \%$ and $18.5 \%$ were tobacco chewers respectively. Alcohol consumption was seen in $32 \%$ of patients and among the ischemic stroke patients $30.1 \%$ cases were alcoholic and hemorrhagic stroke patients $37.0 \%$ were found to be alcoholics.

\section{DISCUSSION}

This study comprised of 100 stroke patients of Vindhya region admitted in the Department of Medicine, Sanjay Gandhi Memorial Hospital, associated with Shyam Shah Medical College, Rewa between April 2018 to June 2019 (15 months). In our study $73 \%$ of all the strokes were due to ischemic stroke where as $27 \%$ of them had haemorrhagic stroke. This is similar to Rajeh SA et al, ${ }^{6}$ in their study they had found ischemic infarction in $76.2 \%$ and haemorrhage in $23.8 \%$ of the stroke in young patients. Sex ratio in our study was 1.3:1 (male: female). Mehndiratta et al $^{7}$ showed a ratio of $1: 1.08$, Zunni et $\mathrm{al}^{8}$ demonstrated a ratio of $1.2: 1$, whereas Chandana et $\mathrm{al}^{9}$ demonstrated a similar ratio of $1.3: 1$ in his study.

The mean age of all the patients in our study was 33.59 years. A study in north India by Mehndiratta et $\mathrm{al}^{7}$ showed a mean age of 31.97 years. The mean ages of males and females were 30.66 and 33.28 years. Our study had a markedly higher mean age group among men at 34.34 years. Whereas among women it was 32.55 years. This difference was probably because there was difference in the sample size. In our study majority of the patients (56\%) were from rural areas as compared to urban areas (44\%). This is primarily due the rural dominance in this part of country and does not seem to indicate a high incidence of stroke in the rural areas. In our study $58 \%$ of the study patients presented with decreased level of consciousness, $27 \%$ patients presented with seizures, $32 \%$ of patients had speech abnormalities and hemiparesis was seen in $83 \%$ patients. In the Bansal et al study ${ }^{10} 57.2 \%$ patients presented with decreased level of consciousness, $28.6 \%$ patients presented with seizures, $30.4 \%$ patients presented with speech abnormalities and $79.2 \%$ patients presented with hemiparesis. In our study $33 \%$ of patients were smokers, among the ischemic and the haemorrhagic stroke patients $39.7 \%$ and $14.8 \%$ were smokers respectively, where as it was $18.11 \%$ and $4.72 \%$ in ischemic and haemorrhagic stroke patients respectively in Mehndiratta et al, ${ }^{7}$ Nagaraja et al ${ }^{11}$ had showed an incidence of smoking associated with stroke to be $15 \%$, Dalal et al ${ }^{12}$ showed $40 \%$, Bogousslavsky et al ${ }^{13}$ calculated $36.6 \%$. There was a significant association between smoking and incidence of ischemic stroke p-value $<0.05$. In our study $30 \%$ of the patients were tobacco chewers, among the ischemic and the haemorrhagic stroke patients it was $34.2 \%$ and $18.5 \%$ respectively. The study of Asplund et al ${ }^{14}$ showed that tobacco chewing was not associated with any apparent excess risk of stroke. The study of Hansson et al ${ }^{15}$ also showed that tobacco chewing was not associated with the risk of stroke. In our study alcohol consumption was seen in $32 \%$ of patients and among the ischemic stroke patients $30.1 \%$ cases were alcoholics and $37.0 \%$ of haemorrhagic stroke patients were found to consume alcohol. In the study of Nagaraja et al ${ }^{11}$ the frequency of alcohol consumption was $15 \%$, according to Dalal et al ${ }^{12}$ was $40 \%$, according to Chandana et $\mathrm{al}^{9} 28.2 \%$ of ischemic stroke and $36.4 \%$ of haemorrhagic stroke, Alverez et al ${ }^{16} 37.8 \%$ of haemorrhagic stroke, where as it was $16.7 \%$ and $28.26 \%$ in ischemic and haemorrhagic stroke respectively in Bevan et al. ${ }^{17}$

\section{CONCLUSIONS}

Stroke in young adults can lead to huge socioeconomic burden on society. In our study we found smoking to be a significant risk factor. So, by countering these addictions at various levels of prevention, we can decrease the incidence of stroke in young adults.

\section{REFERENCES}

[1] Smith WS, Johnston SC, Hemphill JC III. Cerebrovascular diseases In: Kasper DL, Fauci AS, Hauser SL, et al. eds. Harrison's Principles of Internal medicine. 20 $0^{\text {th }}$ edn. New York: McGraw-Hill Publications 2018: p. 3068.

[2] WHO. Stroke, Cerebrovascular accident. 2013. https://www.who.int/topics/cerebrovascular_accident/ en/.

[3] Warlow C, Sudlow C, Dennis M, et al. Stroke. Lancet 2003;362(9391):1211-24.

[4] Strong K, Mathers C, Bonita R. Preventing stroke: saving lives around the world. Lancet Neurol 2007;6(2):182-7.

[5] Béjot Y, Delpont B, Giroud M. Rising stroke incidence in young adults: more epidemiological evidence, more questions to be answered. J Am Heart Assoc 2016;5(5):e003661. 
[6] Al Rajeh S, Awada A, Niazi G, et al. Stroke in a Saudi Arabian National Guard community. Analysis of 500 consecutive cases from a population-based hospital. Stroke 1993;24(11):1635-9.

[7] Mehndiratta MM, Agarwal P, Sen K, et al. Stroke in young adults: a study from a university hospital in north India. Med Sci Monit 2004;10(9):CR535-41.

[8] El Zunni S, Ahmed M, Prakash PS, et al. Stroke: Incidence and pattern in Benghazi, Libya. Ann Saudi Med 1995;15(4):367-9.

[9] Chandana VV, Kalyani N. Clinical profile of stroke among young adults. International Journal of Contemporary Medical Research 2017;4(11):2280-3.

[10] Bansal BC, Prakash C, Jain AL, et al. Cerebrovascular disease in young individuals below the age of 40 years. Neurol India 1973;21(1):11-8.

[11] Nagaraja D, Gurumurthy SG, Taly AB, et al. Risk factors for stroke: relative risk in young and elderly. Neurol India 1998;46(2):183-4.
[12] Dalal PM. Strokes in young and elderly: risk factors and strategies for stroke prevention. J Assoc Phys India 1997;45:125-31.

[13] Bogousslavsky J, Pierre P. Ischemic stroke in patients under age 45. Neurologic Clinics 1992;10(1):113-24.

[14] Asplund K, Nasic S, Janlert U, et al. Smokeless tobacco as a possible risk factor for stroke in men: a nested casecontrol study. Stroke 2003;34(7):1754-9.

[15] Hansson J, Galanti MR, Hergens MP, et al. Snus (Swedish smokeless tobacco) use and risk of stroke: pooled analyses of incidence and survival. J Intern Med 2014;276(1):87-95.

[16] Alvarez J, Matias-Guiu J, Sumalla J, et al. Ischemic stroke in young adults. I. Analysis of the etiological subgroups. Acta Neurologica Scandinavica 1989;80(1):28-34.

[17] Bevan H, Sharma K, Bradley W. Stroke in young adults. Stroke 1990;21(3):382-6. 